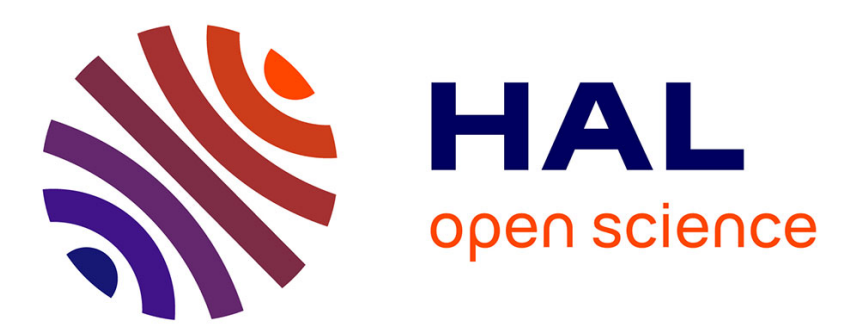

\title{
Seismic damage evaluation and decisions on interventions supported by UAV-based surveys
}

Valeria Croce, Dimitris Diamantidis, Miroslav Sýkora

\section{To cite this version:}

Valeria Croce, Dimitris Diamantidis, Miroslav Sýkora. Seismic damage evaluation and decisions on interventions supported by UAV-based surveys. PROHITECH 2020, 4th International Conference on Protection of Historical Constructions, Oct 2021, Athènes, Greece. hal-03406144

\section{HAL Id: hal-03406144 \\ https://hal.science/hal-03406144}

Submitted on 27 Oct 2021

HAL is a multi-disciplinary open access archive for the deposit and dissemination of scientific research documents, whether they are published or not. The documents may come from teaching and research institutions in France or abroad, or from public or private research centers.
L'archive ouverte pluridisciplinaire HAL, est destinée au dépôt et à la diffusion de documents scientifiques de niveau recherche, publiés ou non, émanant des établissements d'enseignement et de recherche français ou étrangers, des laboratoires publics ou privés. 


\title{
Seismic damage evaluation and decisions on interventions supported by UAV-based surveys
}

\author{
V. Croce ${ }^{1, *}$, D. Diamantidis ${ }^{2}$ and M. Sýkora ${ }^{1}$ \\ ${ }^{1}$ ASTRO Laboratory, Department of Civil and Industrial Engineering (DICI), University of Pisa \\ Largo Lucio Lazzarino, 56122, Pisa (Italy) \\ valeria.croce@unifi.it \\ ${ }^{2}$ Ostbayerische Technische Hochschule, Faculty of Civil Engineering, \\ Galgenbergstrasse 30, 93053 Regensburg, Germany \\ dimitris.diamantidis@oth-regensburg.de \\ ${ }^{3}$ Klokner Institute, Czech Technical University in Prague, \\ Solinova 7, 16608, Prague 6 (Czech Republic) \\ miroslav.sykora@cvut.cz
}

\begin{abstract}
The contribution demonstrates the benefits of Unmanned Aerial Vehicles (UAV)-based surveys for building damage evaluation and decisions on interventions after an earthquake. The case study focuses on the historic village of Castelluccio di Norcia (Italy), heavily damaged by the 2016 earthquake. By constructing a 3D model based on UAV flights, the damage levels are estimated for buildings in the village and an optimal set of intervention measures is proposed. For the decision analysis, a preposterior Bayesian technique is utilized. The efficiency of the UAV-based survey is highlighted through a cost-benefit analysis and by considering parameters such as the time constraints, the quality of obtained data and the risk of inspecting persons. The proposed method seems to be efficient in organizing rescuing activities, managing emergency measures and specifying interventions, following the occurrence of an accidental situation.
\end{abstract}

Keywords: Post-seismic areas, natural hazards, UAV survey, decision analysis.

\section{Introduction}

The study illustrates the application of Unmanned Aerial Vehicles (UAVs, i.e. drones) for surveys of damaged areas, supporting decisions regarding interventions after a seismic event. The proposed methodology is applied to the village of Castelluccio di Norcia, Umbria, Italy that was heavily damaged by the 6.5 magnitude earthquake on October $30^{\text {th }}, 2016$. Shortly after this earthquake, the Fire Brigade utilized UAVs to get a first insight into the extent of the seismic damage. Through the acquisition of videos 
taken by the drones and by extracting frames from videos, the authors reconstruct the 3D model of the damaged village after the earthquake. The modern techniques of Structure from Motion and Multi-View Stereo are applied for photogrammetric surveys. Starting from these 3D data, a map showing the level of damage of each building in the village is developed, using the European Macro-seismic scale EMS-98.

The integrated digital methodology allows consequently deriving a 3D model when terrestrial photogrammetry cannot be applied, and the locations of interest are inaccessible.

The procedure developed in this contribution makes it possible to evaluate degrees of damage and propose an optimal set of intervention measures. The efficiency of the UAV-based is discussed through a pre-posterior Bayesian cost benefit analysis.

The paper starts off from Section 2 where a brief overview of the digital technologies applied to seismic damaged sites is provided. Section 3 presents the seismicity of the Apennines region, with a particular reference to the area of Castelluccio. In Section 4, the steps of the workflow that led to the construction of the two 3D study models are described. Section 5 shows how these 3D models were used for the construction of damage maps and highlights the connection between geomatic survey and disaster management. In Section 6, the reliability level of existing structures is discussed and a relationship between the target reliability and damage level is proposed. In Section 7, the case study is presented, and its results are discussed. Section 8 summarises main findings of this contribution and provides an outlook of further research.

\section{Digital technologies in post-earthquake scenarios}

Nowadays, digital technologies are more and more used to enhance knowledge and documentation on built heritage structures (Croce et al, 2019; 2020a). With the integration of photogrammetry and computer vision, it is possible to develop in a coherent way 3D reality-based models of a site, building or complex of buildings, significantly reducing the time needed for in situ data acquisition, and optimizing subsequent field surveys.

Recent studies have witnessed the application of these restitution techniques even in the case of damage scenarios, in which the presence of risk areas and the uncertainty over the inspectable areas require changes in the timing and methods of on-site surveys (Bevilacqua et al., 2018; Calvano and Guadagnoli, 2016).

As an example, 3D restitution and modeling techniques have been largely applied for the detailed description of damaged buildings and aggregates in Italy, following earthquakes of considerable intensity (Croce et al., 2020b). Italian villages and hamlets affected or threatened by earthquakes are mostly historical buildings, built from stone or brick masonry and even by earth masonry in a few cases, before the definition of rules and methods to guide design and execution of the structures in seismic zones (Sisti et al., 2019; Guidoboni, 2017; Zampilli, 2017; Indirli et al., 2013).

This is why it becomes more and more necessary to introduce numerical evaluation parameters, even expeditious ones, to assess the level of damage to buildings following 
an earthquake. These evaluation metrics should guide the choice of subsequent investigations to be carried out, even directly on site, also for the definition of intervention and recovery plans (Croce et al, 2020b). In the phases of the postintervention emergency, the assessment of damage to buildings plays a key role, making it possible to identify the most critical situations in terms of safety accessibility for rescue teams and experts on surveys.

To evaluate the damage level, different scales have been proposed over time (Calderoni et al., 2020; Sisti et al., 2019; Goretti et al, 2002). In this work, the classification scale provided by the European Macroseismic Scale EMS98 (Grunthal, 1998) is applied since it is considered an indispensable reference tool, at least at European level, to quantify the entity of earthquake-induced damages on masonry buildings. The damage level assessment is carried out considering primarily in-plane failure mechanisms, which are obviously associated to well manifested crack patterns. Note that the proposed method for damage evaluation can be efficiently applied in detecting out-of-plane failures. In the latter case, the mechanisms are identified and analysed when the failures are associated to crack openings; for a general discussion see Asteris et. al. (2014).

Nonetheless, it may happen that the observed damages are not sufficient to directly detect the failure mechanism, or it might be unclear which elements are affected by such mechanism. This may be for instance the case of multiple façades connected on a same building aggregate. In these cases, the proposed method should require the integration with a more detailed analysis, for example with remote sensing techniques such as laser scanning surveys.

\section{Seismicity in the Apennines Region}

Seismicity refers to how often earthquakes of a certain magnitude occur in a particular region. The usual expression relating earthquake magnitudes with their rates of occurrence is the magnitude-frequency relationship by Gutenberg \& Richter (1954). Considering the seismicity history and a domain of engineering interest, the magnitude $M$ in a region can be modelled by a truncated exponential distribution (Campbell, 1985). The cumulative probability distribution is given by:

$$
F(M)=\frac{1-e^{-\beta\left(M-M_{L}\right)}}{1-e^{-\beta\left(M_{U}-M_{L}\right)}}
$$

where $\mathrm{F}(M)$ is the probability of not exceeding magnitude $M, M_{\mathrm{L}}$ is the smallest magnitude of engineering interest (usually $M_{\mathrm{L}}=4.0$ ), $M_{\mathrm{U}}$ is the largest magnitude, which can be expected in the region, and $\beta$ is a site-specific constant. The upper bound $M_{\mathrm{U}}$ may be a random variable. The distribution in Eq. (1) is used in reliability analyses of structures subjected to seismic hazard.

In order to obtain the ground motion at the site it is necessary to adopt a relationship between the seismicity information (magnitudes) and peak ground acceleration (PGA), in terms of hypocentral (or epicentral) distance. If fault-lines are well defined, it may be assumed that the earthquake occurs anywhere along the fault-line with equal probability. 
In many geographical regions, fault locations and their activity are not known. In such cases the distribution of the horizontal distance $R$ from the focus to the site can be calculated under the assumption that focus locations are uniformly distributed over regions of homogeneous seismicity (seismotectonic province).

Based on this, the first part of the workflow adopted here consists of an analysis of data obtained from seismicity catalogues (Luzi et al., 2016; Rovida et al., 2015), geographically referring to the Italian Regions of Umbria, Lazio, Marche and Abruzzi. These data are used as basic input data to estimate earthquake recurrence rates. The estimates are refined by incorporating regional seismicity models and site-specific fault data. Finally, locally adjusted attenuation laws for the horizontal PGA are considered and included in the hazard assessment (Bindi et al., 2011; Ambraseys et al., 2005; Sabetta and Pugliese, 1997).

Fig. 1 shows the location and year of seismic events that occurred in the Apennine area, which has an active tectonic regime running from west to east responsible for the presence of many fault systems in the area (INGV, 2016). The squares and colors refer to the observed values of $M$ while the blue stars identify the location of the 2016 earthquakes epicenters. Fig. 2 displays the cumulative distribution function of the magnitude, taking into account the earthquakes that occurred in the area from 1972 to 2018 with a magnitude $M_{\mathrm{L}}=4.0 \leq M \leq M_{\mathrm{U}}=7.0$.

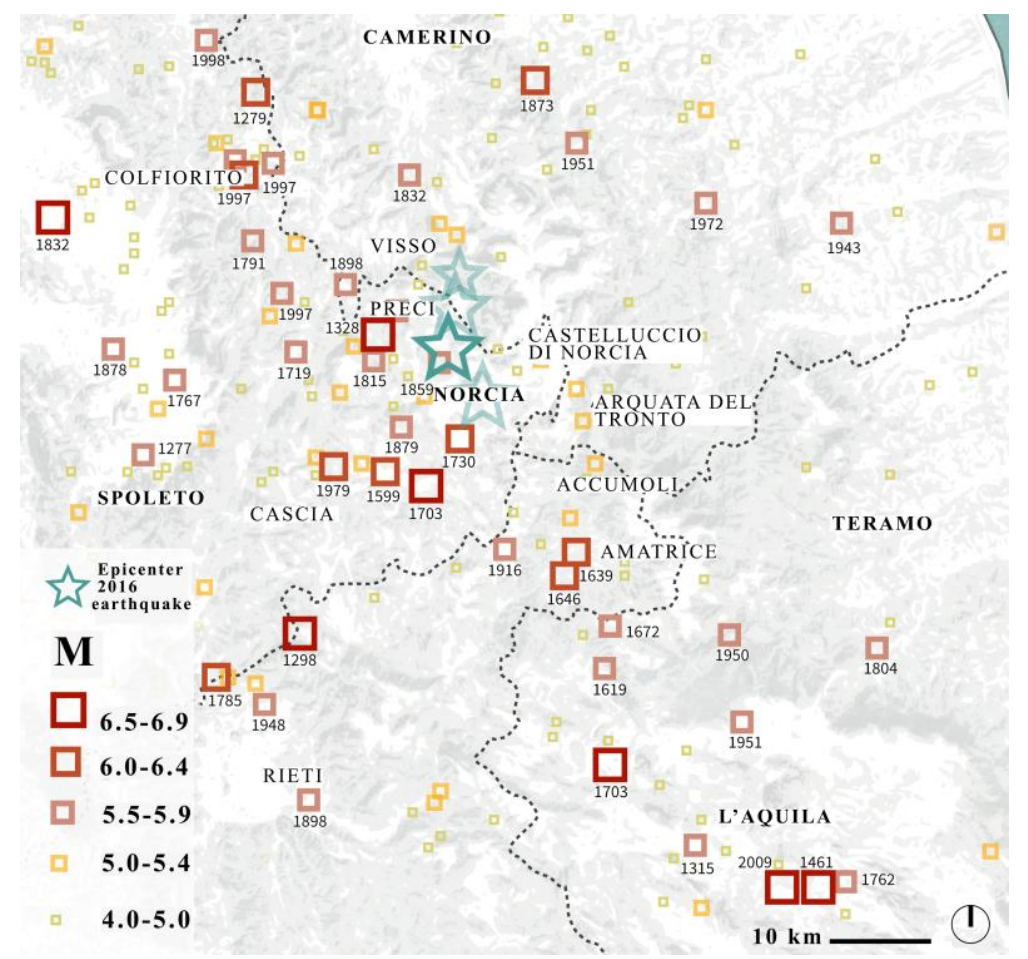

Fig. 1 The Apennine ridge earthquakes (period 1000-2018). 


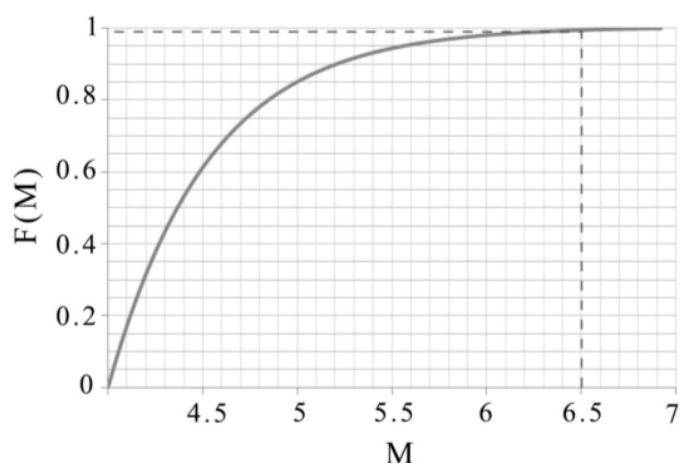

Fig. 2 Cumulative distribution function of the Apennine ridge earthquake magnitude (during the period 1972-2018).

\section{Monitoring information and construction of 3D study models}

In recent years, several studies have been focused on the need to apply geomatics studies in damaged and risky areas. Photogrammetry studies the use of photography in surveying and mapping for the $3 \mathrm{D}$ reconstruction of existing objects. This discipline has undergone considerable developments due to the integration of the techniques of Structure from Motion and Multiple View Stereo, derived from Computer Vision, and has been applied in post-catastrophe situations (Remondino et al., 2011; Caroti et al., 2011).

The use of remotely controlled systems allows to acquire images of damaged zones without the performance of direct inspections in situ, and consequently to reconstructthrough the photogrammetric process - models and maps of disrupted areas. Recent studies on this topic have highlighted the advantages of these techniques, and the importance of geomatics studies to gather aerial information on dangerous and inaccessible sites and to have an accurate and reliable reconstruction of the damage extent (Murtiyoso et al., 2018; Zaragoza et al., 2017; Nex and Remondino, 2014).

The case study of Castelluccio di Norcia represents an emblematic example of application of photogrammetric techniques to damaged scenarios: few hours after the occurrence of the seismic event, the Civil Protection and the Fire Department carried out an aerial reconnaissance of the damage in the village, through the use of UAVs. The results of these flights are videos, which were published few days after the earthquake on the web-site of the Fire Department $<$ www.vigilfuoco.tv $>$. These videos along with another recording dated to many days before the earthquake provided the authors of the paper with the basis for $3 \mathrm{D}$ reconstruction. Even though these videos were originally not recorded for specific survey purposes, the idea is to test their reliability in view of studies of damage identification and subsequent design of intervention measures, using photogrammetry. 
The process led to the construction of the 3D study models (Croce et al., 2019; Croce and Zaragoza, 2018); it consists of the following steps:

1. Video download and consequent extraction of frames: as a first step, the videos are downloaded and frames are extracted, with an average rate of 2 seconds/frame. In total, 146 digital images are obtained for the pre-earthquake model and 334 images for the post-earthquake model.

2. Insertion of Ground Control Points (GCPs): points of known coordinatesGCPs - are inserted on the basis of prior information on the area. In particular, reference is made to a 2004 technical map drafted by the Region of Umbria, in order to detect the X, Y, Z attributes of the GCPs.

3. Camera alignment: the photogrammetric procedures allows to process the digital images.

4. Accuracy assessment: the resulting models present a maximum accepted error of 0.40 meters (compliant with the graphic error) in the determination of GCPs.

5. Dense point cloud generation, mesh generation and texturing: the dense point cloud is generated, then a polygonal mesh model and a texture atlas are constructed both for pre-earthquake (Fig. 3) and post-earthquake (Fig. 4) models.

6. Comparison between the resulting 3D models. The computation of the distances is performed through the CloudCompare, by a cloud-to-mesh comparison tool; the results are displayed in Fig. 5. For most damaged areas, the difference between the two models is higher than 0.9 meters, corresponding to collapsed buildings.

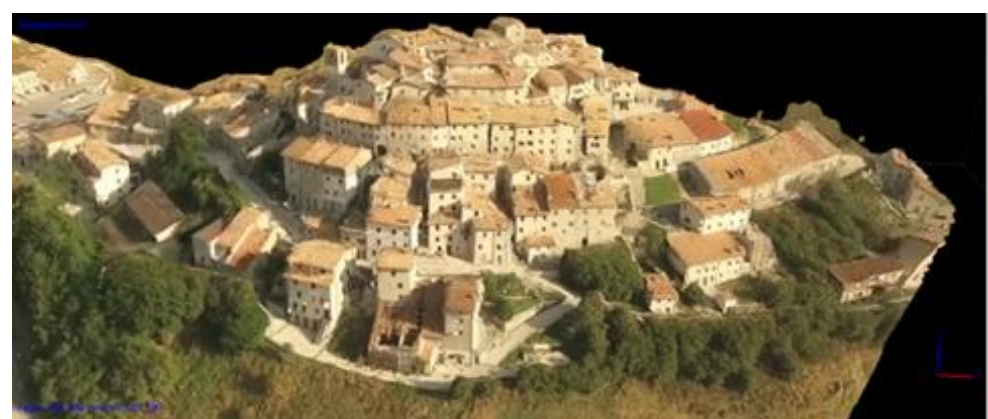

Fig. 3 3D model of the pre-earthquake phase.

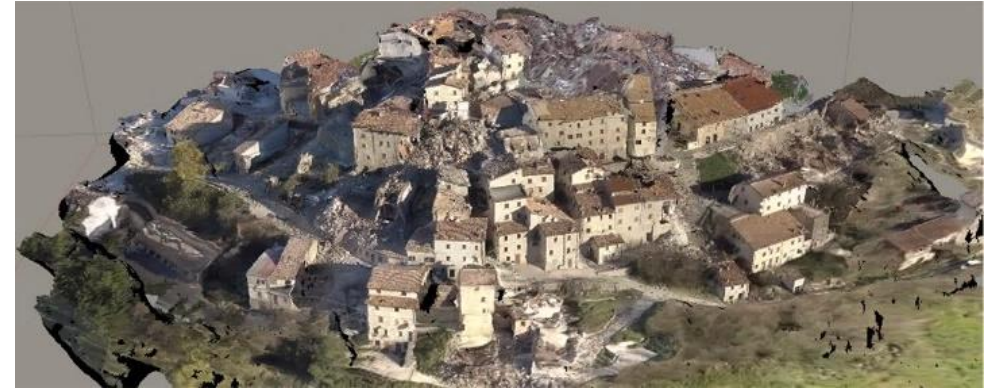

Fig. 4 3D model of the post-earthquake phase. 


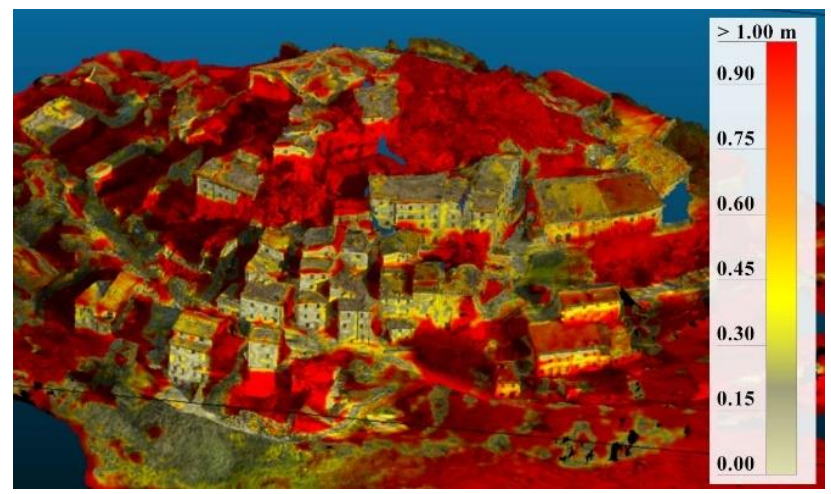

Fig. 5 Cloud-to-mesh comparison: computed distances (Croce et al., 2019).

\section{Importance of Geomatics studies for disaster management}

Strategies for the management and planning of intervention after the occurrence of a disaster are based on the in-depth evaluation of building methods, architectural elements and vulnerability assessment on existing assets. The strategies should also take into account the urban scale and the general layout of cities, villages or minor historical centers; considering these aspects several studies (D'Amico and Currà, 2018; Zampilli, 2017) focused on the impact of catastrophic events at urban level and on the investigation of the characteristics of resilience of urban environments, intended as the capacity of a system to overcome the crisis.

The implementation and development of devices for the management of crisis and emergency phases has been extensively addressed by national and international programs: the United Nations International Strategy for Disaster Risk Reduction (UNISDR, 2012) and the International Recovery Platform discuss the concept of PreDisaster Recovery Planning, i.e. the series of decision and actions taken before and after a disaster, in order to:

- Identify and establish shared recovery goals, objectives and strategies to guide post disaster decision-making, ensure that survey and recovery activities align with long-term development goals, address actual needs, and enhance resilience to future disasters

- Develop and have ready the capacity to plan, initiate and manage; to achieve an efficient, adaptive, and well-coordinated recovery effort that progresses towards the recovery goals.

The Pre-Disaster Recovery Planning is a tool directed towards the planning of recovery and reconstruction programs, in order to direct the communities to build back better after the occurrence of natural hazards. This concept is linked to the structuring of the disaster life cycle (Fig. 6), which includes mitigation and preparedness phases (for prevention) and recovery and response phases (for reconstruction). 


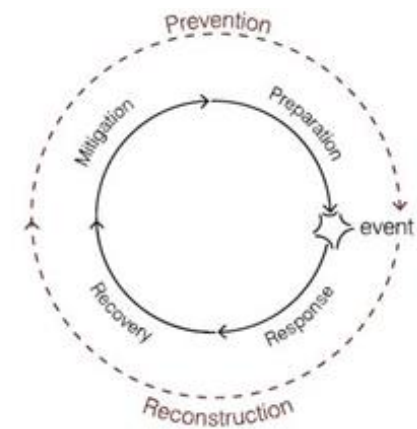

Fig. 6 Disaster life cycle (D’Amico and Currà, 2018)

In this regard, the latest developments in the disciplines of Information and Communication Technologies offer a great potential in supporting the different phases of the disaster life cycle. Aerial acquisition systems, image-based reconstruction, satellite imagery and sensor networks represent nowadays means to support disaster management. They allow a constant and quick monitoring of the areas at risk and environmental hazards and make it possible to gather a huge amount of spatial data even in areas that present safety issues or that are difficult to access and to inspect.

\section{Damage and reliability levels}

Damage to structural elements may be classified into several levels. In order to forecast damage due to an earthquake, it is necessary to learn how various types of structures have behaved when exposed to ground motions of different intensities. The level of damage after a given earthquake depends on vulnerability of the building and on the intensity and duration of the ground motion.

The levels of damage to buildings adopted in this study follow EMS98 (Grünthal, 1998); see Fig. 7. The damage level can be associated to volume and human loss ratios reaching values from $0 \%$ to $100 \%$; see Section 6 .

The damage level can be related to structural reliability and to post-earthquake intervention strategies. A common indicator of the reliability level is the reliability index $\beta$ (indicator equivalent to failure probability).

The reliability of the structure or of its member is sufficient if the reliability index is equal or greater than a target value, normally adopted from relevant standards. EN 1990:2004 for basis of structural design provides the target reliability indexes for three consequence classes CC (small failure consequences CC1, medium CC2 and large CC3) and for two reference periods (1 year and 50 years) without any explicit link to design service life.

The present study deals with existing structures in historical centers. The reliability assessment of existing structures differs from new structures in a number of aspects, 
including possibly lower target reliability levels when safety measure costs are much higher for existing structures in comparison to new structures.

(Caspeele et al., 2017) indicated:

- Minimum target reliability levels $\beta_{\text {ex }}$ below which the existing structure should be upgraded

- Target reliability levels $\beta_{\text {up }}$ for an optimal upgrade strategy

The target reliability levels for different consequence classes, adopted in the case study in Section 6, are provided in Table 1.

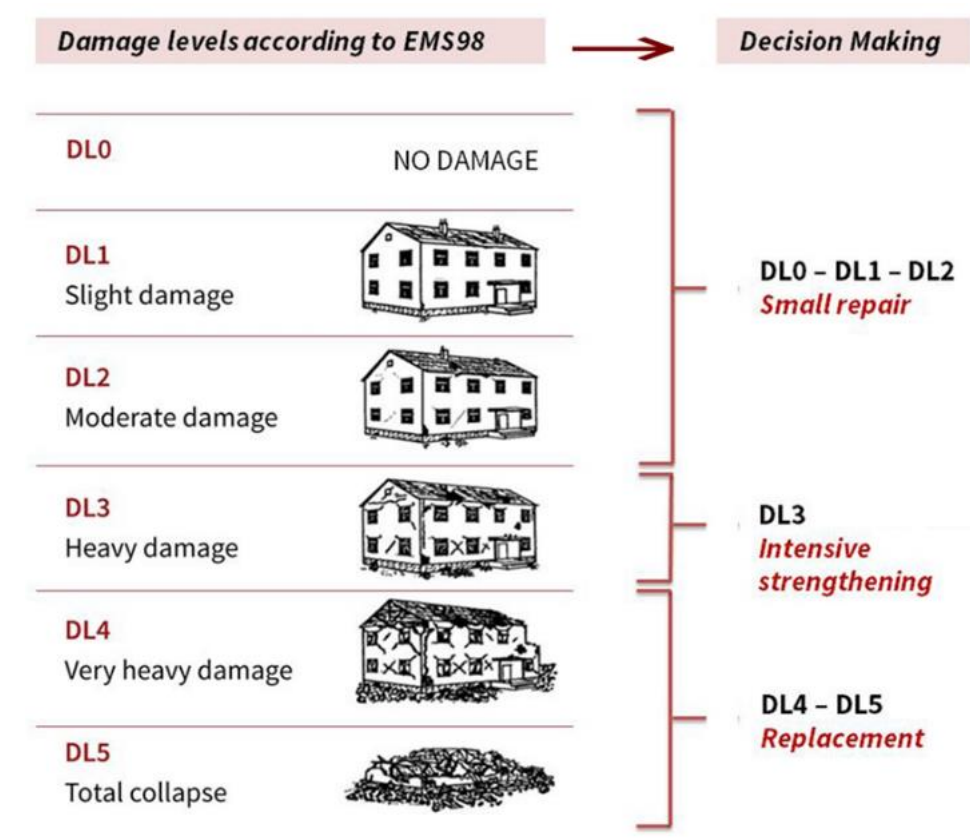

Fig. 7 Damage levels according to (Grünthal, 1998) and associated intervention strategies.

Table 1 Target reliability indices for different consequence classes, (Caspeele et al., 2017; Steenbergen et al., 2015)

\begin{tabular}{llll}
\hline Consequence class & $\boldsymbol{\beta}_{\text {code }}(\mathbf{5 0} \mathbf{y})$. & $\boldsymbol{\beta}_{\text {up }}{ }^{*}$ & $\boldsymbol{\beta}_{\mathbf{e x}}{ }^{*}$ \\
\hline & & & \\
CC1 & 3.3 & 2.8 & 1.8 \\
CC2 & 3.8 & 3.3 & 2.3 \\
CC3 & 4.3 & 3.8 & 2.8 \\
\hline
\end{tabular}

*For a reference period equal to a remaining service life. 


\section{Case study implementation proposal}

In the case study of Castelluccio, the operational procedure to manage the recovery and response phases of the disaster life cycle is based on the definition of a damage level map that is obtained through the outcomes of the UAV-based survey. Several classes of interventions are proposed based on an estimated damage level (Fig. 7).

The data acquired by an UAV-based procedure only are inevitably affected by uncertainties since:

- Aerial acquisitions were originally not aimed at specific needs of building surveys.

- It was impossible to perform checks by physical inspections in situ.

It is thus reasonable to assume that more accurate results would be achieved by combining the UAV-based survey with a terrestrial survey. The distinction between three different approaches to the survey can then be made (Croce, 2018):

Approach 1. UAV-based survey only

Approach 2. Terrestrial survey (physical inspection on the site) only

Approach 3. UAVs combined with terrestrial survey

For the sake of brevity, this study discusses in detail Approach 1 (the only available approach in Castelluccio) and Approach 3 (deemed to provide the best information) only.

In the post-earthquake phase, it is normally necessary to estimate EMS 98 damage levels for affected buildings by performing many surveys in situ. Depending on an estimated damage level, operational decision on appropriate risk reduction measures has then to be made. The study treats both the afore-mentioned aspects.

The approach to survey (Approaches 1 to 3) may affect the results of the damage assessment and consequently decision on interventions. The aspects to be considered when selecting the approach include:

- Costs of survey (inspection), repair, strengthening or replacement

- Time constraints

- Quality of data and possibility to take a wrong decision (based on either underestimation or overestimation of the damage level)

- Risk to experts conducting the survey

The UAV-based survey (Approach 1) is associated with lower costs and times of inspection and does not cause risk to people, but its outcomes may be affected by uncertainties as experts do not physically access the area. The terrestrial survey provides higher quality information, but it is more time consuming and it is related to higher costs since the inspection is made by experts that have to be insured.

This might suggest that the combined methodology (Approach 3) represents the optimum strategy. To confirm this, the so-called pre-posterior cost-benefit analysis is conducted to quantify the value of monitoring and inspections in buildings subjected to 
seismic hazards. For background information see the guidelines for operators, engineers and scientists available at $<$ cost-tu1402.eu/action/deliverables/guidelines $>$.

The reference period is equal to a remaining service life (in the case of repair of an existing building) or to 50 years (upgraded building); the two are considered to be similar and no distinction is further made between them.

Initially, Approach 3 is considered. The related decision tree displayed in Fig. 8 shows that the analysis starts off with estimating occurrence probability of damage level $D L_{i}$, considering prior information about expected consequences of a seismic event; obtained for instance from a Damage Probability Matrix. It is assumed that $D L_{i}$ is assigned without uncertainty using Approach 3. Buildings with $D L 5$ - total collapse - do not require inspections and they are thus disregarded in the following analysis.



Fig. 8 Decision tree for Approach 3.

Depending on the identified damage level, a decision about intervention is made. For the sake of clarity, the following simplifications are adopted:

- For $D L 0$ to $D L 2$ — as identified by the survey — only small repairs are made and a minimum reliability index, $\beta_{\mathrm{ex}}=2.3$ (Table 1), is assumed to be achieved.

- Buildings with $D L 3$ must undergo intensive strengthening that is assumed to ensure $\beta_{\text {code }}=3.8$ for new structures (Table 1 ).

- Buildings classified into $D L 4$ must be replaced and again $\beta_{\text {code }}=3.8$ applies.

After interventions, failure may occur during the reference period with probability $P_{F}$ corresponding to the aforementioned reliability indices $\beta$. Each of the six scenarios in Fig. 8 can then be associated with different costs; the following notation is used:

$P_{i}$ : $\quad$ occurrence probability of damage level $\mathrm{P}\left(D L_{i}\right)$ based on prior information considering previous experience 
$C_{\text {REP }}: \quad$ cost of repairs

$C_{\text {STR }}: \quad$ cost of intensive strengthening

$C_{\text {REPL }}$ : cost of replacement (including demolition and reconstruction costs)

$C_{\text {INSP: }}$ cost of inspection

For Approach 1 imperfect results of a survey and related uncertainty should be considered. A survey may thus over- or underestimate the true $D L$. Probabilities of identifying a (correct or false) damage level $D L_{i}$ given a true $D L_{j}$ should be based on previous experience with applications of the technique in similar cases; expert judgement might be needed in the absence of data. The required input could be a table that provides the likelihoods of correct and false identifications; see the example in Table 2 based on the authors' judgement.

Table 2 Probability of an outcome of the survey given a true $D L_{j}$ (false indications marked underestimation of the true DL in bold, overestimation in grey).

\begin{tabular}{lll}
\hline $\begin{array}{l}\text { True damage } \\
\text { level, } D L_{j}\end{array}$ & $\begin{array}{l}\text { Damage level obtained by } \\
\text { survey, } D L_{i}\end{array}$ & $\begin{array}{l}\text { Probability of identifying } D L_{i} \text { by a survey } \\
\text { given true } D L_{j}, P_{i, \mathrm{UAV}} \mid D L_{j}\end{array}$ \\
\hline$D L 0$ & $D L 0$ & $100 \%$ \\
\hline \multirow{3}{*}{$D L 1$} & $\mathbf{D L O}$ & $\mathbf{1 5 \%}$ \\
& $D L 1$ & $80 \%$ \\
& $D L 2$ & $5 \%$ \\
\hline \multirow{3}{*}{$D L 2$} & $\mathbf{D L 1}$ & $\mathbf{1 5 \%}$ \\
& $D L 2$ & $80 \%$ \\
& $D L 3$ & $5 \%$ \\
\hline \multirow{3}{*}{$D L 3$} & $\mathbf{D L 2}$ & $\mathbf{1 5 \%}$ \\
& $D L 3$ & $80 \%$ \\
$D L 4$ & $D L 4$ & $5 \%$ \\
\hline
\end{tabular}

Table 2 indicates likelihoods for false or correct identification of the true damage level. For instance when a particular building suffered moderate damage $D L 2$, there is:

- $\quad 80 \%$ probability that the UAV-survey would reveal the true level is $D L 2$.

- $15 \%$ probability that $D L 1$ is identified by the UAV-survey; thus a true DL is underestimated.

- $5 \%$ probability that the true damage level is overestimated ( $D L 3)$ by the survey and the decision is to strengthen (while repair should be sufficient).

A pre-posterior cost-benefit analysis can provide the recommendation on an appropriate survey method under particular conditions:

1. The prior occurrence probabilities of a true damage level, $\mathrm{P}\left(D L_{j}\right)=P_{j}$

2. Information about the imprecision of a survey method, $P_{i, \mathrm{UAV}} \mid D L_{j}$

3. Costs related to decisions based on survey outcomes. 


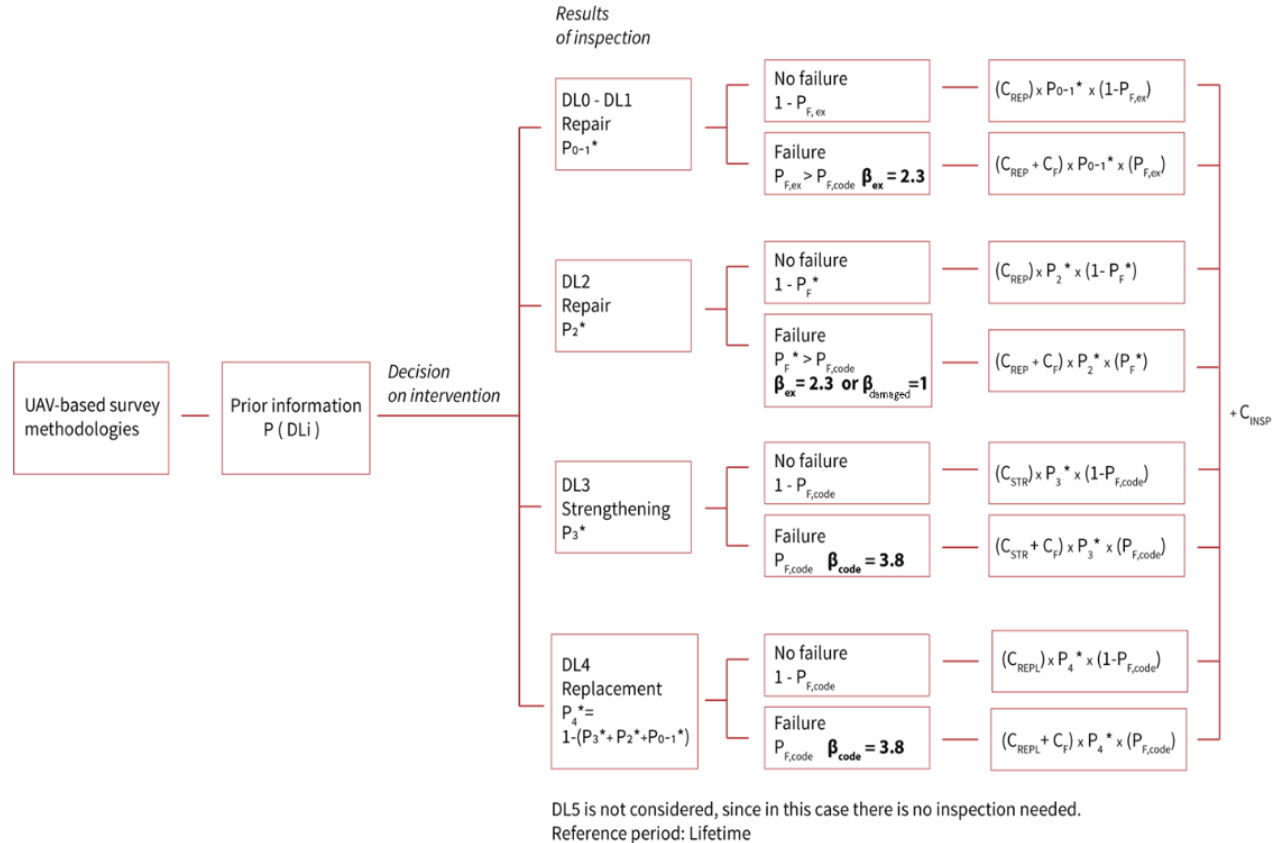

Fig. 9 Decision tree for Approach 1.

In comparison to Approach 3 the decision tree for Approach 1 becomes more complex as it is deemed to be imperfect and aspect 2 needs to be newly introduced. Following the notation in Table 2, the probabilities of identifying a damage level $D L_{i}$ in Fig. 9 are obtained as:

$P_{0-1} *=P_{0, \mathrm{UAV}}\left|D L 0 \times P_{0}+\left(P_{0, \mathrm{UAV}}\left|D L 1+P_{1, \mathrm{UAV}}\right| D L 1\right) \times P_{1}+P_{1, \mathrm{UAV}}\right| D L 2 \times P_{2}$

$P_{2} *=P_{2, \mathrm{UAV}}\left|D L 1 \times P_{1}+P_{2, \mathrm{UAV}}\right| D L 2 \times P_{2}+P_{2, \mathrm{UAV}} \mid D L 3 \times P_{3}$

$P_{3} *=P_{3, \mathrm{UAV}}\left|D L 2 \times P_{2}+P_{3, \mathrm{UAV}}\right| D L 3 \times P_{3}$

$P_{4} *=P_{4, \mathrm{UAV}}\left|D L 3 \times P_{3}+P_{4, \mathrm{UAV}}\right| D L 4 \times P_{4}$

The decision tree in Fig. 9 contains eight scenarios. The most interesting case is when For building(s) under consideration, the costs in Fig. 9 need to be finally estimated and the decision to take Approach 1 or Approach 3 should be based on the comparison of the related total costs.

\section{Conclusions}

This contribution discusses the benefits and drawbacks of Unmanned Aerial Vehicle (UAV)-based surveys in damage evaluation and intervention decisions for residential areas after an earthquake. The case study focuses on the village of Castelluccio di Norcia 
(Italy), heavily damaged by a 2016 earthquake. Videos taken during UAV flights provide essential information for estimating the damage levels for buildings in the village.

The study proposes the methodology linking occurrence probability of a damage level for a particular building, reliability index (or failure probability) for a damaged building and the decision-making on interventions for a particular type of survey. The selection of an optimum survey strategy is supported and the efficiency of the UAV-based survey is highlighted by the results of a pre-posterior Bayesian cost-benefit analysis. The analysis reflects all the key parameters such as the time constraints, the quality of obtained data and the risk of inspecting persons.

Detailed analysis of two different survey strategies reveals that photogrammetric methods along with UAV acquisition makes it possible to acquire spatial data on areas damaged by an earthquake. If necessary, the UAV-based photogrammetry can be supplemented by in-depth in-situ inspections that, however, imply risk to inspectors.

Depending on expected damage, the drawbacks of UAV surveys-limited information on real conditions in the damaged area with possibility to under- or overestimate a damage level - may or may not be traded off by low survey costs and low time demands. The proposed method supports efficient organization of rescuing activities, managing emergency measures and design of interventions in the post-earthquake phases. The methodology can be utilized to manage other accidental situations of historical centers or areas hit by catastrophic events. For important and safety critical structures such as public theatres or hospitals, more detailed studies would be needed. The presented results will be utilized within further research of a disaster life cycle and resilience assessment.

Acknowledgements The present contribution was supported by the Regensburg Centre of Energy and Resources (RCER) of OTH Regensburg, by the Technology and Science Network Oberpfalz (TWO), and by the Ministry of Education, Youth and Sports of the Czech Republic under Grant LTT18003. It is partly based on the thesis by V. Croce, supervised by M. G. Bevilacqua, E. Bascherini, L. Lanini and I. Martinez-Espejo Zaragoza from University of Pisa, and by D. Diamantidis from OTH Regensburg.

\section{References}

Ambraseys N. N., Douglas J., Sarma S. K., Smit P. M. (2005). Equations for the Estimation of Strong Ground Motions from Shallow Crustal Earthquakes Using Data from Europe and the Middle East: Vertical PGA and Spectral Acceleration, in Bull. Earthquake Eng., 3, pp. 1-53.

Asteris P.G., Chronopoulos M.P., Chrysostomou C.Z., Varum H., Plevris V., Kyriakides N., Silva V. (2014). Seismic vulnerability assessment of historical masonry structural systems, in Eng. Struct., 62-63, pp. 118-134. 
Bevilacqua M. G., Caroti G., Piemonte A., Terranova A.A. (2018). Digital technology and Mechatronic Systems for the Architectural 3D Metric Survey, Mechatronics for Cultural Heritage and Civil Engineering, Vol. 92, pp. 161-180

Bindi D., Pacor F., Luzi L., Puglia R., Massa M., Ameri G., Paolucci R. (2011). Ground motion prediction equations derived from the Italian strong motion database, Bull. Earthquake Eng., Vol. 9, pp. 1899-1920.

Calderoni, B., Cordasco, E.A., Del Zoppo, M. et al. (2020) Damage assessment of modern masonry buildings after the L'Aquila earthquake. Bull Earthquake Eng 18, 2275-2301. https://doi.org/10.1007/s10518-020-00784-5

Campbell K. W. (1985). Strong motion attenuation relations: a ten-year perspective, Earthquake Spectra, Vol. 1, 1985, pp. 759-804.

Calvano M., Guadagnoli F. (2016). 3D reconstruction of the city of Amatrice. An "instant modelling” operation, DisegnareCon, Vol. 9, n. 17

Caroti G., Zaragoza I.M.-E., Piemonte A. (2015) Accuracy assessment in structure from motion 3D reconstruction from UAV-born images: The influence of the data processing methods, ISPRS Int. Arch. Photogramm. Remote Sens. Spat. Inf. Sci., 2015, Vol. XL-1-W4, 2015, pp.103-109.

Caspeele R., Steenbergen R., Sýkora M., Allaix D.L., Botte W., Mancini G., Prieto M., Tanner P., Holický M. (2017). Partial Factor Methods for Existing Concrete Structures, (fib bulletin 80). Fédération internationale du béton (fib), fib COM3 TG3.1.

Croce V. (2018). Post-earthquake reconstruction and renewal of urban centres. Case study: Castelluccio di Norcia. Master thesis, Ingegneria Edile-Architettura, Università di Pisa

Croce V., Zaragoza I.M.-E. (2018). UAV-based 3D Photogrammetry for post-Earthquake Studies on Seismic damaged Cities - A Case Study: Castelluccio di Norcia, Proc. IMSCI 2018, pp.7984.

Croce V., Caroti G., Piemonte, A. (2019). Assessment of earthquake-induced damage level on buildings: analysis of two different survey methods for a case study, Int. Arch. Photogramm. Remote Sens. Spatial Inf. Sci., XLII-2/W15, 351-358, doi.org/10.5194/isprs-archives-XLII-2W15-351-2019, 2019

Croce V., Caroti G., Piemonte A., Bevilacqua M.G.B. (2019). Geomatics for Cultural Heritage conservation: Integrated survey and 3D modeling, Proc. of the IMEKO TC4 International Conference on Metrology for Archaeology and Cultural Heritage, MetroArchaeo, Dec. 4-6, 2019, Florence, Italy, pp. 271-276. MetroArcheo Florence

Croce V., Caroti G., De Luca L., Piemonte A., Véron, P. (2020a) Semantic annotations on heritage models: 2D/3D approaches and future research challenges. ISPRS - Int. Arch. Photogramm. Remote Sens. Spat. Inf. Sci, TCII/WG8, XLIII-B2-2020, 829-836, doi:10.5194/isprs-archivesXLIII-B2-2020-829-2020.

Croce V., Diamantidis D., Sýkora M. (2020b) Planning post-earthquake surveys: assessment and reconstruction of small historical centers, in: Proceedings of the IABSE Symposium, Synergy of Culture and Civil Engineering, Wroclaw, Poland, Oct. 7-9, 2020, pp. 332-339

D'amico A. and Currà E. (2018). Resilienza urbana dei centri storici italiani. Strategie di pianificazione preventiva, Techne. Ricerca e sperimentazione, 15, 2018 
Goretti A., Di Pasquale G. (2002). An overview of post-earthquake damage assessment in Italy, in: EERI Invitational workshop, An action plan to develop earthquake damage and loss data protocol, Sep. 19-20, 2002, Pasadena, California

Grünthal G. (1998) European Macroseismic Scale 1998 (EMS-98), Center Europèen de Géodynamique et de Séismologie, Luxembourg, 1998.

Gruppo di lavoro INGV sul terremoto in Centro Italia, Summary report on the October 30th, 2016 earthquake in central Italy Mw 6.5 doi:10.5281/zenodo. 16623

Guidoboni E. (2017). Il valore della memoria. Terremoti e ricostruzioni in Italia nel lungo periodo, Quellen und Forschungen aus italienischen Archiven und Bibliotheken, Volume 96, Issue 1, pp. 415-444, doi.org/10.1515/qfiab-2016-0020, 2017.

Gutenberg, B. and Richter, C.F. (1954). Seismicity of the Earth and Associataed Phenomena., Princeton University Press, Princeton, NJ, USA.

Indirli M, Kouris S, Formisano A, Borg RP, Mazzolani FM (2013) Seismic damage assessment of unreinforced masonry structures after the abruzzo 2009 earthquake: the case study of the historical centers of L'Aquila and Castelvecchio Subequo. Int J Archit Herit 7(5):536-578

Luzi L, Puglia R, Russo E (2016). ORFEUS WG5, Engineering Strong Motion Database, INGV, Observatories \& Research Facilities for European Seismology.

Murtiyoso, A., Grussenmeyer, P., Suwardhi, D., Awalludin, R. (2018). Multi-Scale and MultiSensor 3D Documentation of Heritage Complexes in Urban Areas, ISPRS Int. Geo-Inf., 7 (12), 483, doi.org/10.3390/ijgi7120483

Nex, F. and Remondino, F. (2014). UAV for 3D mapping applications: a review, Applied Geomatics, Volume 6, Issue 1, pp. 1-15.

Pugliano A. (2017). La ricostruzione del patrimonio immateriale nei luoghi danneggiati dai terremoti, in Ricerche di storie dell'arte, 2, Maggio-Agosto 2017, Società editrice Il Mulino, Bologna, pp. 23-35

Remondino F., Barazzetti L., Nex F., Scaioni M., Sarazzi D. (2011). UAV Photogrammetry for Mapping and 3D Modeling, ISPRS Int. Arch. Photogramm. Remote Sens. Spat. Inf. Sci., 2011, Vol. XXXVIII-1/C22, 25-31, doi.org/10.5194/isprsarchives-XXXVIII-1-C22-25-2011, 2011.

Rovida A., Locati M., Camassi R., Lolli B., Gasperini P. (2015). CPTI15, Parametric Catalogue of Italian Earthquakes, Istituto Nazionale di Geofisica e Vulcanologia INGV.

Sabetta F., and Pugliese A. (1997) Estimation of response spectra and simulation of non-stationary earthquake ground motion, Bull. Seismol. Soc. Amb., Vol. 86, No. 2, pp. 337-352.

Sisti R., Di Ludovico M., Borri A., Prota A. (2019) Damage assessment and the effectiveness of prevention: the response of ordinary unreinforced masonry buildings in Norcia during the Central Italy 2016-2017 seismic sequence. Bull Earthq Eng 17(10):5609-5629

Steenbergen M., Sýkora M., Diamantidis D., Holický M., Vrouwenvelder T. (2015). Economic and human safety reliability levels for existing structures, Structural concrete, journal of the fib, Vol. 16, No. 3, pp. 323-332

Sýkora M., Diamantidis D., Holický M., Jung K. (2017). Target reliability for existing structures considering economic and societal aspects, Structure and Infrastructure Engineering, Vol. 13, n. 1, pp. 181-194

UNITED NATIONS OFFICE FOR DISASTER RISK REDUCTION (UNISDR, 2012). Annual report 2012, Geneva, Switzerland, 2012 
Zampilli M. (2017). Come affrontare il processo di ricostruzione dei centri storici, Ricerche di storia dell'arte, 2, Maggio-Agosto 2017, Società editrice Il Mulino, Bologna.

Zaragoza, I.M.-E., Caroti, G., Piemonte, A., Riedel, B., Tengen, D., Niemeier, W. (2017). Structure from motion (SfM) processing of UAV images and combination with terrestrial laser scanning, applied for a 3D-documentation in a hazardous situation, Geomatics, Natural Hazards and Risk, 8 (2), pp.1492-1504, https://doi.org/10.1080/19475705.2017.1345796. 